\title{
SUBSTANCE USE AMONG EUROPEAN STUDENTS: EAST - WEST COMPARISON BETWEEN 1995 AND 2011
}

\author{
Alojz Nociar ${ }^{1}$, Janusz Sieroslawski ${ }^{2}$, Ladislav Csémy ${ }^{3}$ \\ 1Department of Psychology, St. Elisabeth University of Health and Social Work, Bratislava, Slovak Republic \\ Institute of Psychiatry and Neurology in Warsaw, Warsaw, Poland \\ ${ }^{3}$ Prague Psychiatric Centre, Prague, Czech Republic
}

\section{SUMMARY}

Aim: The aim of the study was to investigate long-term trends differences in student substance misuse between countries of former Eastern Bloc (FEB) and Western Europe (WEST). Overall data on student substance misuse gathered in five waves of the European School Survey Project on Alcohol and other Drugs (ESPAD) conducted between 1995 and 2011 were pooled and analysed. Findings were compared between FEB and WEST countries at the five time-points of data collection.

Methods: Over 396,000 of 16 years old students from thirteen FEB and thirteen WEST countries completed anonymous ESPAD questionnaires. The following data were compared by Wilcoxon test: proportion of students with experience of taking a legal drug at less than 13 years of age (early onset), regular tobacco use, emerging signs of alcohol abuse, and differences in prevalence of illegal drug use.

Results: Significant differences in selected variables were found in the early onset of legal and illegal drug use between FEB and WEST countries. On the contrary, no significant differences were present when several random samples from the pool of 26 participating countries were drawn and compared. This strengthens our confidence that the differences between FEB and WEST countries did not occur due to chance.

Conclusions: Student drug use in FEB countries tended to follow the trends and patterns of legal and illegal drug use in WEST countries with some time lag. At the times of decline in use of both, legal and illegal substances in the WEST countries, the FEB countries were experiencing increase and later on stabilisation in drug use. The possible explanatory factors including the impact of profound political, cultural and socio-economic changes following the fall of the Iron Curtain in 1989 were discussed. The implications of these trends and suggestions for drug prevention strategies were outlined.

Key words: ESPAD survey, alcohol and drug use, early onset, East - West comparison

Address for correspondence: A. Nociar, Department of Psychology, St. Elisabeth University of Health and Social Work, Palackého 1, 81000 Bratislava, Slovak Republic. E-mail: nociar@vssvalzbety.sk

http://dx.doi.org/10.21101/cejph.a4309

\section{INTRODUCTION}

Drug situation in Europe in the late 1980s and early 1990s varied between countries of former Eastern Bloc (FEB) and the West European countries (WEST). Initially, FEB mostly experienced problems with alcohol and tobacco. Difficulties with illegal drug use were much less prevalent. For example, Poland and the Czech Republic were challenged by home-made drugs such as "compote" heroin from Poland (a mixture of opiate alkaloids) (1), and "pervitin" (a methamphetamine "cooked" from ephedrine) in the Czech Republic (2). The character of substance misuse in the rest of Europe was different. It is possible that the problems with alcohol and tobacco may have been alleviated by increases in its price, tax and other forms of alcohol and tobacco market regulation $(3,4)$. However, the black market with illegal drugs still flourished in these countries at those times.

It appears that the "Iron curtain" served not only as a political, economical and cultural division but also as a barrier for supply and demand of legal and illegal drugs. It was to be expected that the changes in social, political and economic systems would affect the character and severity of substance use and misuse in FEB.
During this period, the drug prevention, new and drug-specific treatments, harm reduction and aftercare were not yet well developed. For these reasons we anticipated substantial vulnerability among our youth.

The increase in drug use has started since 1991 in vast majority of FEB countries and it was firstly documented by the Pompidou Group (5). It is believed that the fall of socialistic regimes, the beginning of civil war in former Yugoslavia, its partition and the post-war situation could have contributed to this increase. Consequently, the drug supply and demand increased, fed by drug smuggling via the Northern branch of Balkan route. Initially, FEB appeared to serve as transit states, but most of them very soon have become user states. Initially, black market appeared to be dominated by heroin, later on with cannabis, amphetamines, ecstasy and other synthetic drugs, leading up to present day new synthetic drugs.

The lack of preparedness of health, school and law enforcement systems to quickly and effectively handle this new situation created by drug smuggling and sudden availability of illegal drugs on black market was a common denominator in vast majority of FEB (6). 
The initial idea to study differences in onset of drug use between the two groups of European countries developed thanks to an observation of opposite drug use trends between some FEB (earlier age of onset of drinking and smoking) and WEST countries (later age of onset) during the Scientific Committee Working Group (further only Group) of the European Alcohol and Health Forum. The main task of the group was to investigate the impact of marketing advertisement on the volume of alcohol intake and drinking patterns of young people (7). However, the advertisement of legal drugs was not the only possible factor contributing to the above mentioned earlier onset of smoking and drinking.

Many studies analysed the effects of various types of advertisements of alcohol and other drugs on young people. These investigations looked at the relationship between early onset of drinking and drug use later in life. For example joint effect of exposure to advertising at grade 6 was predictive of grade 7 drinking and intentions to drink (8). Another study demonstrated the connection of alcohol use displayed in movies and early onset of drinking (9). Similar phenomena of early onset of substance use under 13 years of age were observed among youth in some FEB countries. A backward comparison of the Health Behaviour of School Children (HBSC) and the European School Survey Project on Alcohol and other Drugs (ESPAD) surveys in Poland can serve as an example (10).

Sudden transit of illicit drugs through once impassable borders in FEB after 1989 influenced new generation born one decade prior to or just before these changes. In fact, the cohorts of the first three ESPAD waves were born in 1979, 1983 and 1987 (11-13). As socialist regimes in FEB countries were coming to the end, in some respect, the childhood of these cohorts was gradually becoming shorter due to being subjected to attacks of commercially targeted advertisements of 'adult substance use behaviours'. In these commercial advertisements, even already known legal drugs like coffee, tobacco and alcohol were offered in much more attractive and marketable new packaging.

It appears that the above described situation had taken its toll on this transit generation which was demonstrated in growing numbers of demands for drug addiction treatment and drug related deaths observed mostly in big cities and capitals of FEB in the early 1990s. This pattern was typical for heroin epidemics in Slovakia's capital Bratislava and in many other European cities up to the end of 20th century, as documented in several Pompidou Group summaries from the epidemiology expert group's members Hartnoll, Bless, and Nociar $(5,6,14)$.

The aim of this manuscript was to add further information (perhaps not fully noticed before) to the knowledge we already have about those transition times.

\section{MATERIALS AND METHODS}

\section{Sample}

The sample consisted of more than 479,000 sixteen years old students from all participating ESPAD countries. The sample sizes per each year of data collection ranged from more than 74,000 in 1995 to over 103,000 students in 2011 (Table 1). The ESPAD survey project methodology used national samples of randomly selected schools and/or classes in which the cohort of students born in the same year completed anonymous questionnaires with several core and some country specific questions regarding drug prevalence. Thereafter completed questionnaires in sealed envelopes and unique school and class code were delivered to ESPAD research teams for processing. The data for our analysis were sources from the appendices of published ESPAD reports where the results were presented per country in given year of data collection, usually published with one year delay $(11-13,15,16)$.

\section{Outcome Measures}

Variables selected for present study were divided into three groups:

Early onset of legal and illegal drug use:

- First cigarette at the age of 13 or earlier;

- First glass of beer at the age 13 or earlier;

- First glass of wine at the age 13 or earlier;

- First glass of spirit at the age 13 or earlier;

- Daily smoking at the age of 13 or earlier;

- Smoking cannabis at the age of 13 or earlier.

Recent use/abuse of tobacco and alcohol during last 30 days:

- Regular smoking during last 30 days (1-5 cigarettes or more per day);

- Drinking beer during last 30 days (1-2 or more times);

- Drinking wine during last 30 days (1-2 or more times);

- Drinking spirits during last 30 days (1-2 or more times);

- Excessive drinking (5+ during last occasion 3-5 or more times during 30 days).

Prevalence and perceived availability/risk of illicit drugs:

- Lifetime prevalence of any illicit drug (marihuana or hashish, LSD, amphetamines, crack, cocaine, stimulants, tranquilizers);

- Lifetime prevalence of any illicit drug, except of marihuana or hashish;

- Lifetime and last year prevalence of cannabis;

- Lifetime prevalence of ecstasy;

- Perceived availability of cannabis ("easy" to "very easy");

- Perceived risk of cannabis ("great risk").

Table 1. Overall number of students in all ESPAD countries and in 13 FEB and 13 WEST countries

\begin{tabular}{|l|c|c|c|c|c|}
\hline ESPAD countries/FEB - WEST & $\mathbf{1 9 9 5}$ & $\mathbf{1 9 9 9}$ & $\mathbf{2 0 0 3}$ & $\mathbf{2 0 0 7}$ & $\mathbf{2 0 1 1}$ \\
\hline Number of all ESPAD countries & 26 & 30 & 35 & 35 & 36 \\
\hline Total number of students & 77,010 & 91,223 & 102,964 & 104,828 & 103,076 \\
\hline Number of all FEB countries & 9 & 13 & 13 & 13 & 13 \\
\hline Total number of students & 38,656 & 43,520 & 43,330 & 35,485 & 37,618 \\
\hline Number of all WEST countries & 12 & 13 & 13 & 13 & 13 \\
\hline Total number of students & 35,718 & 37,734 & 37,424 & 47,178 & 39,571 \\
\hline
\end{tabular}




\section{Statistical Methods}

Variables were coded into small SPSS file and the data from 1995 to 2011 were entered for each of the 26 countries. SPSS 20 was used for data coding, processing and analysis.

For the purpose of analysis, participating countries were sorted into two groups: the countries of Central and Eastern Europe from former Eastern Bloc and the old West/North/ South European countries which had been preferably collecting data from the initial launch of ESPAD survey in 1995. Only the countries that participated in at least four waves were included in the analysis. The thirteen FEB were: Bulgaria, Czech Republic, Croatia, Estonia, Hungary, Latvia, Lithuania, Poland, Romania, Russian Federation, Slovakia, Slovenia, and Ukraine. The thirteen WEST countries were: Cyprus, Denmark, Faroe Islands, Finland, Greece, Iceland, Ireland, Italy, Malta, Norway, Portugal, Sweden, and UK.

In order to strengthen our confidence in validity of our findings, we made further comparisons between the countries based on parameters other than their geo-political classification: we randomly selected three pairs of groups from the overall pool of 26 countries for further comparison; 26 countries were divided into two groups according to the sizes of their population (less than 10 million or close to 10 million, versus more than 10 million inhabitants).

The first pair of thirteen FEB and thirteen WEST countries was labelled as "Bloc". Then three random pairs of groups, selected by drawing lots (countries numbered from 1 to 26), were labelled as "Random 1", "Random 2" and "Random 3". The fourth pair labelled "Size" was selected according to the sizes of their populations, as mentioned above. These five combinations of 26 countries (Bloc, Random 1, Random 2, Random 3, and Size) were compared by nonparametric tests for two independent samples and nonparametric tests for two independent groups - Mann-Whitney U-test and Wilcoxon test were performed.

\section{RESULTS}

There were many significant differences between thirteen FEB versus thirteen WEST countries, in contrast to four randomly selected groups and the groups selected by population size where no such differences were found.

Table 2 shows the percentage means selected variables for the FEB and WEST countries in five data collection time points:

The most visible differences between the FEB and WEST countries, or opposite trends over five ESPAD waves, were in the first and second group of variables, i.e. early onset of use and recent use or the last month prevalence (LMP). But contrary to our expectations, there were fewer differences in the lifetime prevalence, perceived substance availability and risk.

The comparison in the group of FEB and WEST countries showed significant differences in the first experience with cigarette at 13 years of age or younger. The means for FEB were significantly higher than for WEST countries in 2003, 2007 and 2011. No significant differences were found between randomly selected groups and the groups selected by population size apart from one exception in Random 2 variable for the year 2007 $(\mathrm{p}<0.043)$. Anyhow, from 20 tests 19 were non-significant (Table 3, Fig. 1).
The first experiences with drinking beer and wine at 13 or earlier were in both cases significantly higher in FEB in the years 2003, 2007 and 2011. No significant differences were found between randomly selected groups and the groups selected by population size (Fig. 2, 3).

As for daily smoking at 13 or less, there was increase in FEB and decline in WEST groups, with opposite starting point in 1995 and significant differences in the years 2007 and 2011. No

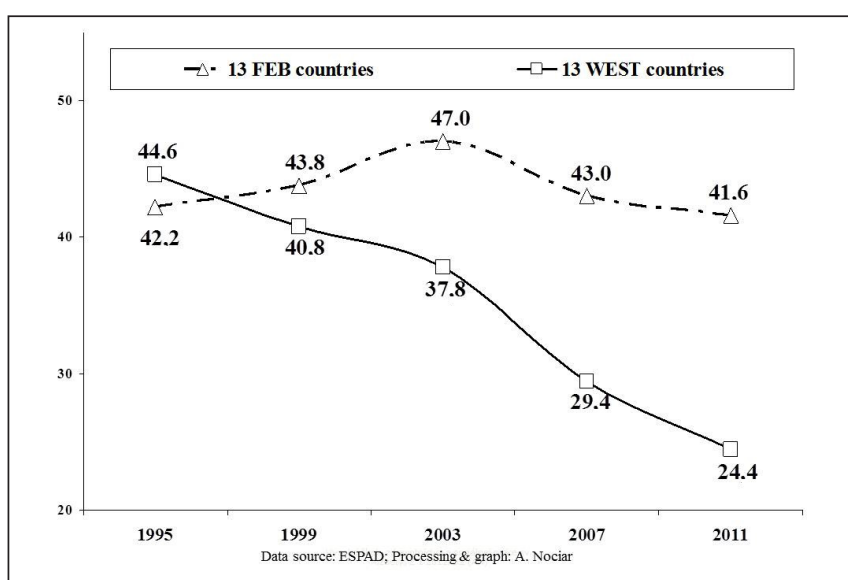

Fig. 1. Trends in ESPAD variables 1995-2011, 1st cigarette tried at 13 or earlier (\%).

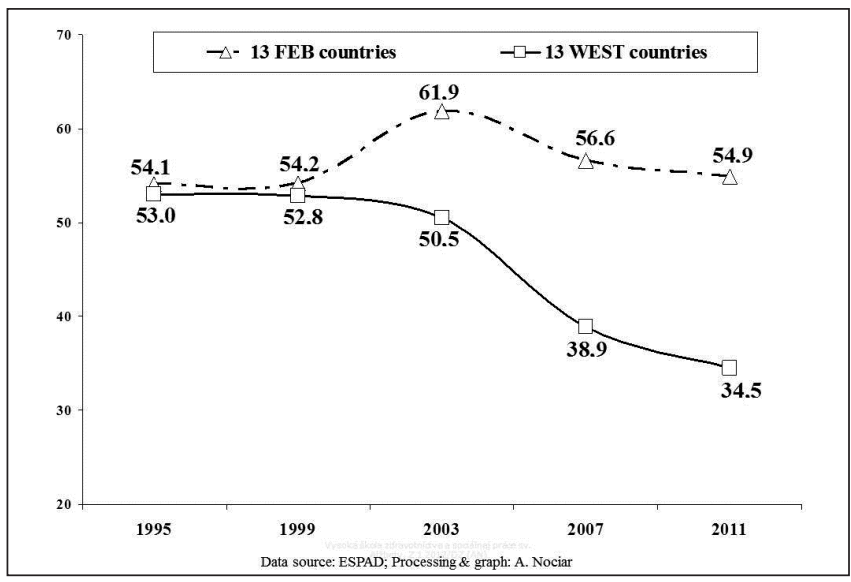

Fig. 2. Trends in ESPAD variables 1995-2011, glass of beer tried at 13 or earlier (\%).

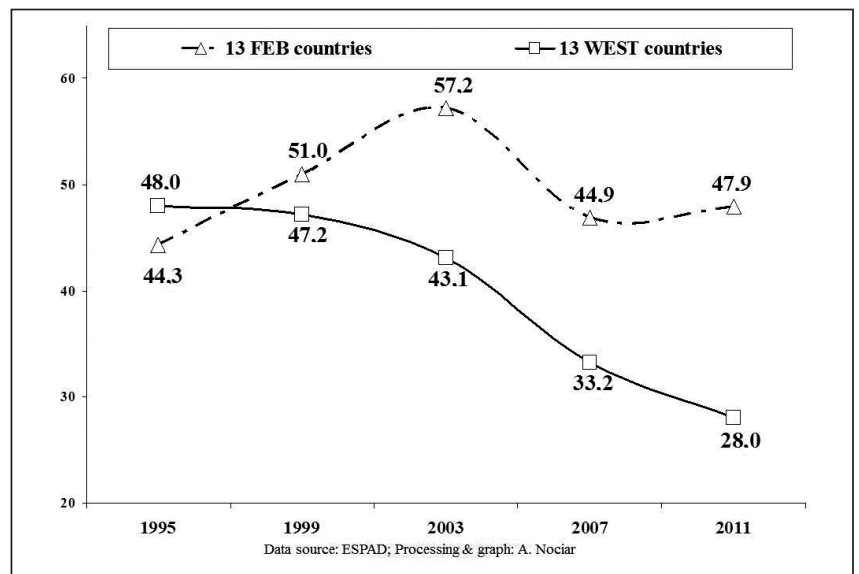

Fig. 3. Trends in ESPAD variables 1995-2011, glass of wine tried at 13 or earlier (\%). 
Table 2. Mean percentages of selected variables for CEECs and WEST countries in five time points

\begin{tabular}{|c|c|c|c|c|c|c|}
\hline ESPAD countries: CEEC - WEST* & & 1995 & 1999 & 2003 & 2007 & 2011 \\
\hline \multirow{2}{*}{ First cigarette at the age of 13 or earlier } & FEB & 42.2 & 43.8 & 47.0 & 43.0 & 41.6 \\
\hline & WEST & 44.6 & 40.8 & 37.8 & 29.4 & 24.4 \\
\hline \multirow{2}{*}{ First glass of beer at the age of 13 or earlier } & FEB & 54.1 & 54.2 & 61.9 & 56.6 & 54.9 \\
\hline & WEST & 53.0 & 52.8 & 50.5 & 38.9 & 34.5 \\
\hline \multirow{2}{*}{ First glass of wine at the age of 13 or earlier } & FEB & 44.3 & 51.0 & 57.2 & 46.9 & 47.9 \\
\hline & WEST & 48.0 & 47.2 & 43.1 & 33.2 & 28.0 \\
\hline \multirow{2}{*}{ First glass of spirit at the age of 13 or earlier } & FEB & 23.0 & 24.9 & 30.3 & 23.7 & 24.7 \\
\hline & WEST & 30.8 & 30.7 & 37.2 & 20.5 & 19.9 \\
\hline \multirow{2}{*}{ Daily smoking at the age of 13 or earlier } & FEB & 7.8 & 9.2 & 11.2 & 8.8 & 9.5 \\
\hline & WEST & 11.2 & 10.8 & 10.3 & 6.4 & 5.5 \\
\hline \multirow{2}{*}{ Smoking cannabis at the age of 13 or earlier } & FEB & 0.8 & 1.9 & 3.3 & 4.0 & 3.8 \\
\hline & WEST & 3.3 & 3.2 & 3.8 & 3.1 & 2.6 \\
\hline \multirow{2}{*}{ Regular smoking during last 30 days } & FEB & 20.3 & 26.9 & 27.4 & 22.9 & 22.5 \\
\hline & WEST & 20.8 & 21.3 & 20.5 & 15.0 & 13.5 \\
\hline \multirow{2}{*}{ Drinking beer during last 30 days } & FEB & 35.2 & 51.7 & 56.1 & 52.0 & 51.7 \\
\hline & WEST & 51.0 & 53.3 & 49.3 & 44.5 & 39.3 \\
\hline \multirow{2}{*}{ Drinking wine during last 30 days } & FEB & 36.1 & 44.8 & 44.0 & 38.5 & 42.8 \\
\hline & WEST & 35.0 & 34.8 & 32.9 & 30.0 & 25.8 \\
\hline \multirow{2}{*}{ Drinking spirits during last 30 days } & FEB & 37.1 & 37.8 & 41.2 & 38.2 & 41.0 \\
\hline & WEST & 45.2 & 49.6 & 52.3 & 43.1 & 39.9 \\
\hline \multirow{2}{*}{ Binge drinking ( $5+$ drinks $3-5+$ times in 30 days) } & FEB & 10.1 & 12.3 & 15.8 & 16.9 & 16.6 \\
\hline & WEST & 16.6 & 19.6 & 18.7 & 18.3 & 15.2 \\
\hline \multirow{2}{*}{ Lifetime prevalence of any illicit drug** } & FEB & 10.3 & 19.3 & 21.8 & 22.9 & 22.9 \\
\hline & WEST & 14.4 & 16.0 & 16.2 & 14.4 & 13.9 \\
\hline \multirow{2}{*}{ Lifetime prevalence of any illicit drug ${ }^{* * *}$} & FEB & 2.6 & 7.6 & 5.7 & 7.7 & 6.8 \\
\hline & WEST & 5.6 & 5.4 & 5.1 & 6.2 & 5.2 \\
\hline \multirow{2}{*}{ Lifetime prevalence of cannabis } & FEB & 9.7 & 16.7 & 21.1 & 21.1 & 21.3 \\
\hline & WEST & 14.3 & 15.0 & 16.2 & 13.1 & 12.5 \\
\hline \multirow{2}{*}{ Lifetime prevalence of ecstasy } & FEB & 0.4 & 2.8 & 3.3 & 4.2 & 2.9 \\
\hline & WEST & 3.2 & 2.5 & 2.9 & 2.7 & 2.1 \\
\hline \multirow{2}{*}{ Perceived availability of cannabis: easy/very easy } & FEB & 16.4 & 25.2 & 31.8 & 35.7 & 33.4 \\
\hline & WEST & 29.1 & 33.0 & 37.1 & 30.6 & 27.9 \\
\hline \multirow{2}{*}{ Perceived risk of cannabis: great } & FEB & 52.7 & 46.1 & 37.6 & 37.6 & 35.9 \\
\hline & WEST & 41.2 & 41.2 & 34.2 & 36.6 & 34.0 \\
\hline
\end{tabular}

*Instead of "Bloc" label used in SPSS testing the label "CEEC - WEST" is used in Tables

**Marihuana or hashish, LSD, amphetamines, crack, cocaine, stimulants, tranquilizers

${ }^{* * *}$ Except of marihuana or hashish

significant differences were found between randomly selected groups and the groups selected by population size apart from 2 exceptions in daily smoking variable (anyhow, from 20 tests 18 were non-significant). In spite of this, trend was clearly visible: in 1995 were FEB $3.8 \%$ lower, but in 2011 were $4.0 \%$ higher than WEST in daily smoking (Fig. 4).

The same was true for recent regular smoking of cigarettes and drinking of wine last 30 days among 16 year olds: increase in FEB, decline in WEST countries in the years 1999, 2003, 2007 and 2011. No significant differences were found between randomly selected groups and the groups selected by population size (Fig. 5, 6).
The comparison of FEB and WEST countries showed significant differences in excessive drinking ( $5+$ drinks $3-5$ times in 30 days) in the years 1995-1999. At these time points the FEB group was significantly lower than the WEST group. In the next three waves, FEB were catching up with the WEST countries and in 2011, the both groups were abusing alcohol at the same level. No significant differences were found between randomly selected groups and the groups selected by population size (Fig. 7).

The comparison of illegal drug use between the FEB and WEST countries showed significant differences in composite index for use of all illicit drugs in the lifetime for the years 2007 and 2011, and all illicit drugs apart from marihuana for the year 


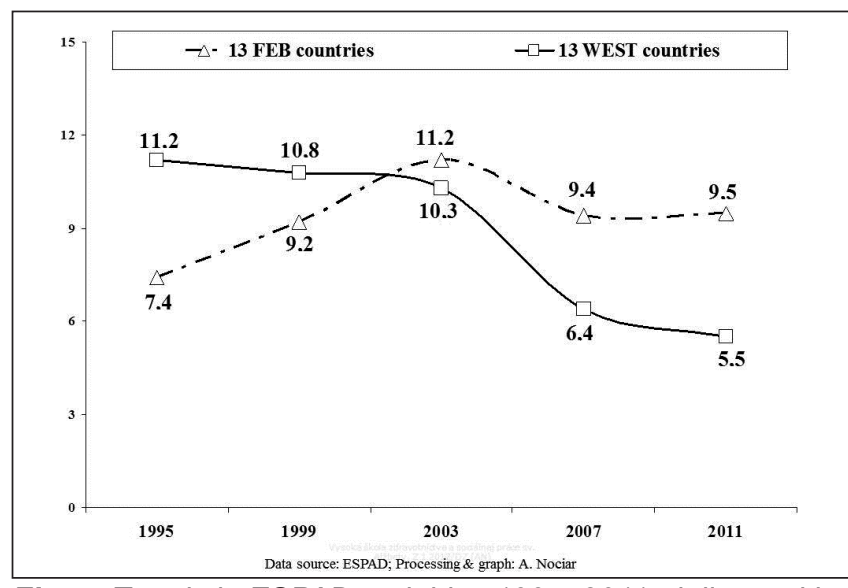

Fig. 4. Trends in ESPAD variables 1995-2011, daily smoking of tobacco at 13 or earlier (\%).

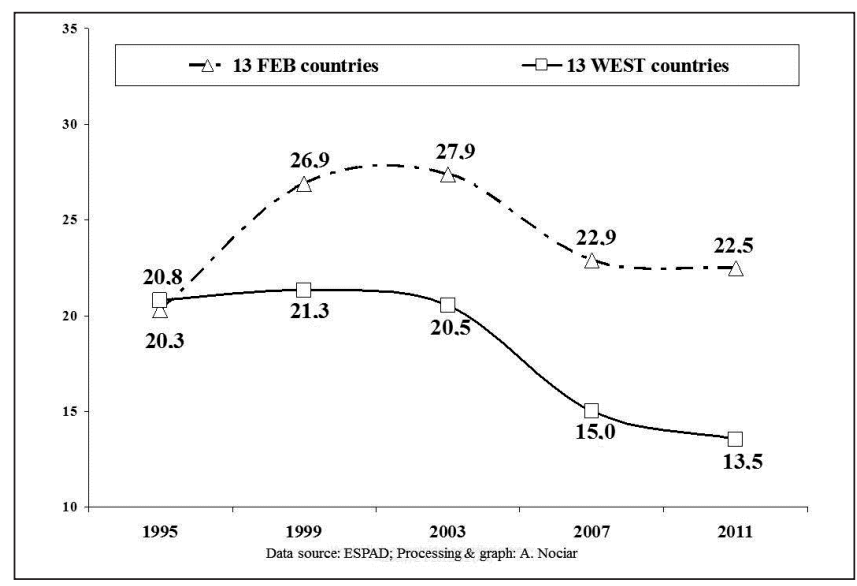

Fig. 5. Trends in ESPAD variables 1995-2011, smoking 1-5 and more cigarettes per day during last 30 days (\%).

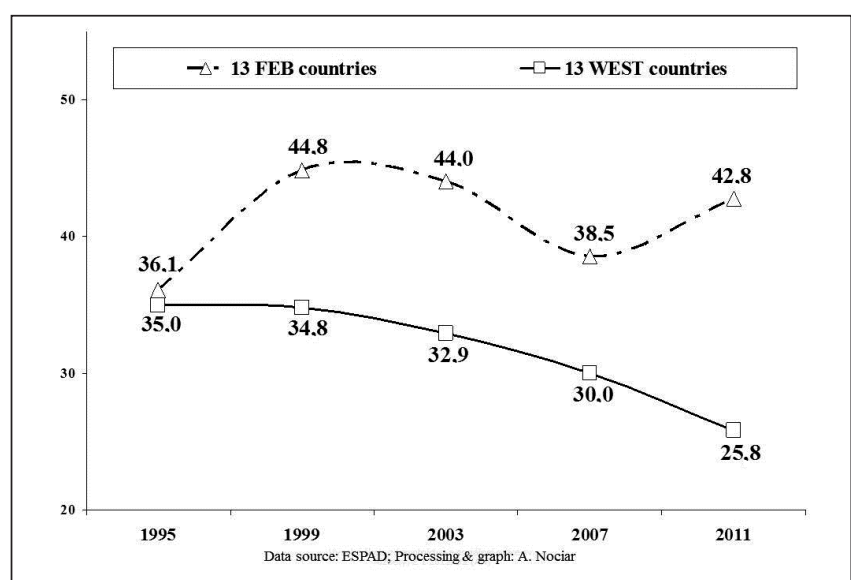

Fig. 6. Trends in ESPAD variables 1995-2011, drinking 1-2 and more glasses of wine during last 30 days (\%).

1999 (when FEB observed higher rates of use than WEST). There were no significant differences between randomly selected groups and the groups selected by population size (Fig. 8).

Lifetime prevalence of cannabis had similar trajectory as lifetime prevalence of any drug use, i.e. FEB documented significantly higher lifetime prevalence in the years 2007 and 2011. As for ecstasy, beginning and end-points were significantly different, with opposite signs (at first FEB low, and in the end high).

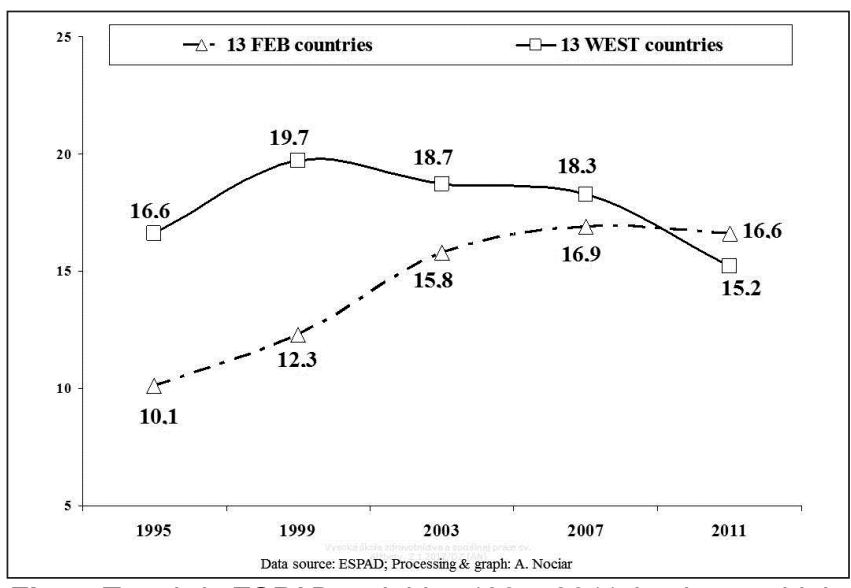

Fig. 7. Trends in ESPAD variables 1995-2011, having 5+ drinks 3-5 or more times last 30 days.

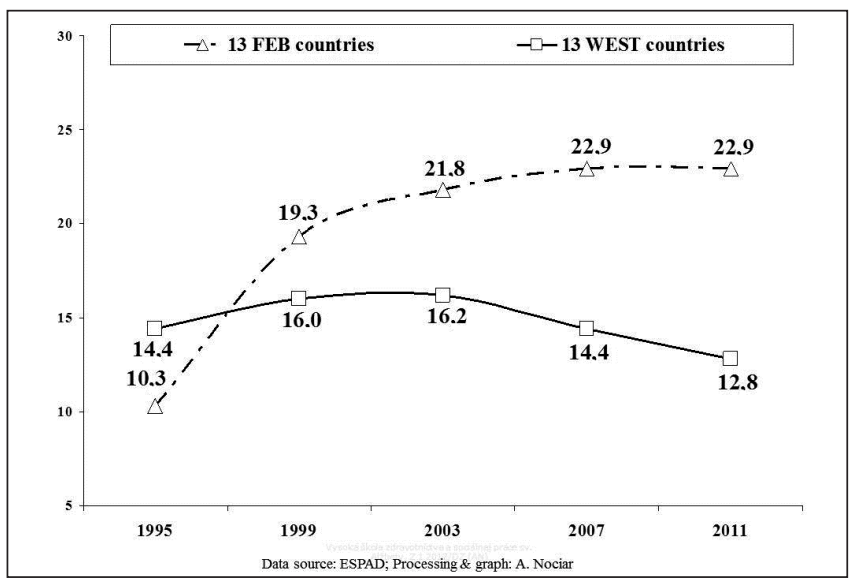

Fig. 8. Trends in ESPAD variables 1995-2011, any illicit drug - lifetime prevalence.

However, the perceived availability of cannabis did not reach statistical significance and perceived great risk of occasional use did reach it only once - in 2007 (all results, tested for significance, are summarized together in Table 3 ).

To summarize tests of significance: from 340 tests performed with Random 1, 2, 3 and Size only in 3 tests $(0.9 \%)$ differences between groups were significant and in the rest of tests null hypothesis was confirmed. From 85 tests comparing FEB and WEST, 33 tests $(38.8 \%)$ were significant and disconfirmed null hypothesis. This was quite strong indicator of different trends in substance use among youngsters between two groups of European countries during 1990s and after 2000.

\section{DISCUSSION AND CONCLUSION}

It appears that the political, economic and social changes in FEB (further only changes) after 1989 opened the way for new transit routes and rise of black market with illegal drugs. These events appear to have influenced attitudes and behaviours of new generation born ten to two years before these changes. Following a short period of childhood these children had before the socialist regimes in their countries came to an end, they experienced a sudden exposure to new and unknown illegal substances and commercially targeted products. They were also literally flooded 
Table 3. Differences between five pairs of countries in selected ESPAD variables

\begin{tabular}{|c|c|c|c|c|c|}
\hline Year/variable & 1995 & 1999 & 2003 & 2007 & 2011 \\
\hline \multicolumn{6}{|c|}{ Early onset of licit and illicit drugs use } \\
\hline Groups/Signif. & \multicolumn{5}{|c|}{ First cigarette at the age of 13 or earlier } \\
\hline FEB - WEST & 0.651 & 0.687 & 0.029 & 0.001 & 0.000 \\
\hline Random $1,2,3^{*}$ & $\mathrm{~ns}^{* *}$ & ns & ns & ns 0.043 ns & ns \\
\hline \multirow[t]{2}{*}{ Size } & ns & ns & ns & ns & ns \\
\hline & \multicolumn{5}{|c|}{ First glass of beer at the age 13 or earlier } \\
\hline FEB - WEST & 0.972 & 0.579 & 0.007 & 0.000 & 0.000 \\
\hline Random 1,2,3 & ns & ns & ns & ns & ns \\
\hline \multirow[t]{2}{*}{ Size } & ns & ns & ns & ns & ns \\
\hline & \multicolumn{5}{|c|}{ First glass of wine at the age 13 or earlier } \\
\hline FEB - WEST & 0.754 & 0.418 & 0.007 & 0.012 & 0.001 \\
\hline Random 1,2,3 & ns & ns & ns & ns & ns \\
\hline \multirow[t]{2}{*}{ Size } & ns & ns & ns & ns & ns \\
\hline & \multicolumn{5}{|c|}{ First glass of spirit at the age 13 or earlier } \\
\hline FEB - WEST & 0.058 & 0.287 & 0.840 & 0.204 & 0.169 \\
\hline Random 1,2,3 & ns & ns & ns & ns & ns \\
\hline \multirow[t]{2}{*}{ Size } & ns & ns & ns & ns & ns \\
\hline & \multicolumn{5}{|c|}{ Daily smoking at the age of 13 or earlier } \\
\hline FEB - WEST & 0.096 & 0.390 & 0.511 & 0.022 & 0.006 \\
\hline Random 1,2,3 & ns & ns & ns & ns 0.016 ns & ns 0.016 ns \\
\hline \multirow[t]{2}{*}{ Size } & ns & ns & ns & ns & ns \\
\hline & \multicolumn{5}{|c|}{ Smoking cannabis at the age of 13 or earlier } \\
\hline FEB - WEST & 0.020 & 0.614 & 0.840 & 0.204 & 0.139 \\
\hline Random 1,2,3 & ns & ns & ns & ns & ns \\
\hline Size & ns & ns & ns & ns & ns \\
\hline \multicolumn{6}{|c|}{ Recent use/abuse of tobacco and alcohol during last 30 days } \\
\hline Groups/Signif. & \multicolumn{5}{|c|}{ Regular smoking during last 30 days ( $1-5$ cigarettes or more per day) } \\
\hline FEB - WEST & 0.862 & 0.034 & 0.003 & 0.002 & 0.000 \\
\hline Random 1,2,3 & ns & ns & ns & ns & ns \\
\hline \multirow[t]{2}{*}{ Size } & ns & ns & ns & ns & ns \\
\hline & \multicolumn{5}{|c|}{ Drinking beer during last 30 days ( $1-2$ or more times) } \\
\hline FEB - WEST & 0.006 & 0.960 & 0.101 & 0.113 & 0.012 \\
\hline Random 1,2,3 & ns & ns & ns & ns & ns \\
\hline \multirow[t]{2}{*}{ Size } & ns & ns & ns & ns & ns \\
\hline & \multicolumn{5}{|c|}{ Drinking wine during last 30 days (1-2 or more times) } \\
\hline FEB - WEST & 0.702 & 0.007 & 0.019 & 0.113 & 0.05 \\
\hline Random 1,2,3 & ns & ns & ns & ns & ns \\
\hline \multirow[t]{2}{*}{ Size } & ns & ns & ns & ns & ns \\
\hline & \multicolumn{5}{|c|}{ Drinking spirits during last 30 days ( $1-2$ or more times) } \\
\hline FEB - WEST & 0.129 & 0.016 & 0.012 & 0.390 & 0.801 \\
\hline Random 1,2,3 & ns & ns & ns & ns & ns \\
\hline Size & ns & ns & ns & ns & ns \\
\hline
\end{tabular}


Continued from previous page

\begin{tabular}{|c|c|c|c|c|c|}
\hline Year/variable & 1995 & 1999 & 2003 & 2007 & 2011 \\
\hline & \multicolumn{5}{|c|}{ Excessive drinking (5+ during last occasion $3-5$ or more times during 30 days) } \\
\hline FEB - WEST & 0.006 & 0.007 & 0.336 & 0.733 & 0.574 \\
\hline Random 1,2,3 & ns & ns & ns & ns & ns \\
\hline Size & ns & ns & ns & ns & ns \\
\hline \multicolumn{6}{|c|}{ Prevalence and perceived availability/risk of illicit drugs } \\
\hline Groups/Signif. & \multicolumn{5}{|c|}{ Lifetime prevalence of any illicit drug ${ }^{* *}$} \\
\hline FEB - WEST & 0.917 & 0.139 & 0.139 & 0.044 & 0.001 \\
\hline Random 1,2,3 & ns & ns & ns & ns & ns \\
\hline \multirow[t]{2}{*}{ Size } & ns & ns & ns & ns & ns \\
\hline & \multicolumn{5}{|c|}{ Lifetime prevalence of any illicit drug, except of marihuana or hashish } \\
\hline FEB - WEST & 0.508 & 0.044 & 0.579 & 0.264 & 0.072 \\
\hline Random 1,2,3 & ns & ns & ns & ns & ns \\
\hline \multirow[t]{2}{*}{ Size } & ns & ns & ns & ns & ns \\
\hline & \multicolumn{5}{|c|}{ Lifetime prevalence of cannabis } \\
\hline FEB - WEST & 0.702 & 0.287 & 0.125 & 0.050 & 0.007 \\
\hline Random 1,2,3 & ns & ns & ns & ns & ns \\
\hline \multirow[t]{2}{*}{ Size } & ns & ns & ns & ns & ns \\
\hline & \multicolumn{5}{|c|}{ Lifetime prevalence of ecstasy } \\
\hline FEB - WEST & 0.012 & 0.336 & 0.479 & 0.064 & 0.039 \\
\hline Random 1,2,3 & ns & ns & ns & ns & ns \\
\hline \multirow[t]{2}{*}{ Size } & ns & ns & ns & ns & ns \\
\hline & \multicolumn{5}{|c|}{ Perceived availability of cannabis ("easy" to "very easy") } \\
\hline FEB - WEST & 0.069 & 0.243 & 0.614 & 0.223 & 0.287 \\
\hline Random 1,2,3 & ns & ns & ns & ns & ns \\
\hline \multirow[t]{2}{*}{ Size } & ns & ns & ns & ns & ns \\
\hline & \multicolumn{5}{|c|}{ Perceived risk of occasional use of cannabis ("great risk") } \\
\hline FEB - WEST & 0.095 & 0.448 & 0.336 & 0.840 & 0.614 \\
\hline Random 1,2,3 & ns & ns & ns & ns & ns \\
\hline \multirow[t]{2}{*}{ Size } & ns & ns & ns & ns & ns \\
\hline & \multicolumn{5}{|c|}{ Perceived risk of regular use of cannabis ("great risk") } \\
\hline FEB - WEST & 0.917 & 0.418 & 0.336 & 0.005 & 0.064 \\
\hline Random 1,2,3 & ns & ns & ns & ns & ns \\
\hline Size & ns & ns & ns & ns & ns \\
\hline
\end{tabular}

ns = not significant; significant $=$ bold letters

*If all Random1,2,3 are not significant, only one "ns" is in a row, in other case there is a number

${ }^{* *}$ Any illicit drug = marihuana/hashish, LSD, amphetamines, crack, cocaine, stimulants, tranquilizers

with new advertisements of already well known legal drugs like coffee, tobacco and alcohol, which were offered in much more attractive and marketable new packaging.

This is what happened after socioeconomic and political changes took place in FEB in the end of the 1980s. The five waves of ESPAD survey from 1995 to 2011 can be utilized as one of the documents depicting these processes, which were often reflected in the opposite trends between these two groups of countries such as increase in proportion of those with early onset of legal drug use and growth of illegal drug use prevalence in FEB, versus decline of the same in WEST (which were free of such turbulent events).
The same can be said about the observed recent substance use during last month as well as about early and recent regular use of tobacco and signs of recent excessive drinking among whole samples of 16 year olds. However, the effects of those great changes have gradually vanished away. The socioeconomic environment and trends between two groups of countries past 2000 have grown more similar thanks to globalization and more recent problems related to economic crisis. However, as our data indicated, legal and illegal drug use trajectories of FEB were still not fully in line with the second group of Western countries in 2007 and 2011. It will be interesting how these trends might change by the next ESPAD wave in 2015. 
The practical implications of our findings are numerous. Firstly, the early prevention programmes should target the children before they reach their teens. Several studies have argued for early drug prevention, which ought to be implemented before contact with legal drugs for the intervention to be effective. For example, Pentz et al. conducted a multi-community trial for primary prevention of adolescent drug abuse at 42 schools, where "The most promising programmes seem to be those that are initiated in the early adolescent years, particularly the years marking transition to middle or junior high school (sixth or seventh grade), and that focus on delaying the onset or abuse of one or more of the 'gateway drugs' (tobacco, alcohol, and marijuana)... The early adolescent years have been identified as the first risk period for use of these drugs" (17).

Secondly, the attempt to delay onset of legal and illegal drug use might be a valuable target in this teenage population. This was already documented in our previous studies (18), where those who smoked their first tobacco cigarette at the age of 11 or younger, later tried their first marihuana much earlier in life than those who started later on: "Students who on average smoked their first tobacco cigarette at 11 years or younger, smoked their first marihuana cigarette at 14 and half; but if they smoked it as 13 year olds, they started with marihuana at 15 and one quarter; and if they started at 15, the first marihuana followed (among the same students) at the age of 15 and three quarters" (18). Nociar concluded that in order to delay the first contact with marihuana for six months it is needed to delay the first contact with tobacco for at least one year.

Broadly speaking, our results appear to reflect the impact of political and socioeconomic changes following 1989 on legal and illegal drug use among youth in FEB. Student drug use in FEB countries tended to follow the trends and patterns of legal and illegal drug use in WEST countries with some time lag. At the times of decline in use of both, legal and illegal substances in the WEST countries, the FEB countries were experiencing increase (at least up to 2003), and later stabilization (between 2007 and 2011) of drug use.

\section{Acknowledgements}

Our thanks belongs to professor Ludwig Kraus for his valuable technical advice in drafting this study, and to Mgr. Stanislava Šaffová, MSc for her keen and kind contribution to improvement of structure and more proper wording of the final version.

\section{REFERENCES}

1. Sierosławski J, Ostrihansky R. National report Poland: Phare project on drug information systems, final phase. Amsterdam: eesv MSDP; 1998.

2. Zábranský V. Methapmhetamine in the Czech Republic. J Drug Issues. 2007;37(1):155-80
3. Edwards G, et al. Alcohol policy and the public good. Oxford: Oxford University Press; 1994.

4. Anderson P, Baumberg B. Alcohol in Europe: a public health perspective. London: Institute of Alcohol Studies; 2006.

5. Hartnoll R. Multi-city network Eastern Europe. Joint Pompidou Group/ UNDCP project: extension of the multi-city network to Central and Eastern Europe. First city reports from: Bratislava; Budapest; Gdansk; Ljubljana; Prague; Sofia; Szeged; Varna; Warsaw. Strasbourg: Council of Europe Publishing; 1997.

6. Bless R. 3rd Multi-city Study. Drug use trends in European cities in the 1990s. Strasbourg: Council of Europe Publishing; 2001.

7. Anderson P, Foxcroft DR, Kaner E, Martinic M, Moskalewicz J, Nociar A. Does marketing communication impact on the volume and patterns of consumption of alcoholic beverages, especially by young people? A review of longitudinal studies. In: Scientific Opinion of the Science Group of the European Alcohol and Health Forum; 2009 Feb 23; Brussels.

8. Collins RL, Ellickson PL, McCaffrey D, Hambarsoomians K. Early adolescent exposure to alcohol advertising and its relationship to underage drinking. J Adolesc Health. 2007 Jun;40(6):527-34.

9. Sargent JD, Wills TA, Stoolmiller M, Gibson J, Gibbons FX. Alcohol use in motion pictures and its relation with early-onset teen drinking. J Stud Alcohol. 2006 Jan;67(1):54-65.

10. Dudek M, Kasznia-Kocot J, Giel K. Trends of selected health behaviors of Polish youth aged 13-15 the European and worldwide studies between 1995-2011. Medycyna Środowiskowa. 2015;18(2):74-80. (In Polish.)

11. Hibell B, Andersson B, Bjarnason T, Kokkevi A, Morgan M, Narusk A. The 1995 ESPAD report. Alcohol and other drug use among students in 26 European countries. Stockholm: Swedish Council for Information on Alcohol and Other Drugs; 1997.

12. Hibell B, Andersson B, Ahlström S, Balakireva O, Bjarnason T, Kokkevi A, et al. The 1999 ESPAD report. Alcohol and other drug use among students in 30 European countries. Stockholm: Swedish Council for Information on Alcohol and Other Drugs; 2000.

13. Hibell B, Andersson B, Bjarnason T, Ahlström S, Balakireva O, Kokkevi A, et al. The 2003 ESPAD report. Alcohol and other drug use among students in 35 European countries. Stockholm: Swedish Council for Information on Alcohol and Other Drugs; 2004.

14. Nociar A. Extension of the treatment demand indicator from city to national level in the countries of Central and Eastern Europe. Final report (P-PG/Epid (2000)4). Strasbourg: Council of Europe Pompidou Group; 2001.

15. Hibell B, Guttormsson U, Ahlström S, Balakireva O, Bjarnason T, Kokkevi A, et al. The 2007 ESPAD report. Substance use among students in 35 European countries. Stockholm: Swedish Council for Information on Alcohol and Other Drugs; 2009.

16. Hibell B, Guttormsson U, Ahlström S, Balakireva O, Bjarnason T, Kokkevi A, et al. The 2011 ESPAD report. Substance use among students in 36 European countries. Stockholm: Swedish Council for Information on Alcohol and Other Drugs; 2012.

17. Pentz MA, Dwyer JH, MacKinnon DP, Flay BR, Hansen WB, Wang EY, et al. A multicommunity trial for primary prevention of adolescent drug abuse. Effects on drug use prevalence. JAMA. 1989 Jun 9;261(22):325966.

18. Nociar A. Surveys on drugs, alcohol and tobacco in Slovak youth. Bratislava: Veda; 2004. (In Slovak.) 